\title{
Examining Potential Travel Time Savings Benefits Due to Toll Rates That Vary by Lane
}

\author{
Negin Alemazkoor, Mark Burris \\ Zachry Department of Civil Engineering, Texas A \& M University, College Station, USA \\ Email: n-alemazkoor@ttimail.tamu.edu, mburris@tamu.edu
}

Received 2 March 2014; revised 1 April 2014; accepted 19 April 2014

Copyright (C) 2014 by authors and Scientific Research Publishing Inc.

This work is licensed under the Creative Commons Attribution International License (CC BY). http://creativecommons.org/licenses/by/4.0/

(c) (i) Open Access

\begin{abstract}
By assigning different toll rates to different lanes during peak traffic hours, the demand for each lane of a road can be optimized. Lanes with lower travel times charge higher toll rates which are paid by those drivers who have higher values of travel time (VTT) and who want to avoid congestion in the other lanes. Conversely, travel time for those drivers with lower values of travel times will increase as they select the lower priced and slower lanes. This research examines toll rates that minimize the total value of travel time spent on the road under such a scenario. The optimum toll rates are dependent on the total road volume and distribution of VTT. The results show that total saved value of travel time can easily reach $11 \%$ of the total value of time spent traveling on the lanes when compared to a toll road with a uniform toll rate for all lanes. These savings vary based on many factors including the number of travelers on urgent trips.
\end{abstract}

\section{Keywords}

Differential Toll Rates, Travel Time Savings, Value of Travel Time

\section{Introduction}

Fiscal constraint on transportation infrastructure expenditures has many agencies considering managed lanes (MLs) to optimize the use of those lanes and provide travelers with high values of travel time (VTT) an uncongested alternative. This research expands on that idea and examines a scenario where most lanes of a roadway are managed. This research examines the travel time savings derived from offering different toll rates on different lanes of the same road. This allows those drivers with high VTT to select, and pay for, the lanes with lower travel times. This concept will be tested on the Veterans Expressway in the Tampa Bay area in 2016

(http://www.tollroadsnews.com/node/6250).

To estimate the distribution of vehicles in different lanes with different toll rates, VTT distributions are 
needed. In this research, distributions developed by Patil et al. are used [1]. These rates were developed through a survey of travelers along the Katy Freeway in Houston. The Katy Freeway had managed lanes and thus those respondents were already familiar with the option of paying more for a faster trip.

Different toll rates could influence other costs besides travel time because changes in speeds led to changes in the amount of fuels consumed and emissions produced. However, in many benefit-cost analyses for variable and dynamic tolling, the costs or benefits from changing fuel consumption or emissions were found to be very small compared to benefits from travel time savings [2] [3]. Therefore, in this research, only the change in travel time savings is investigated.

\section{Literature Review}

Poole discussed the challenges of freeway pricing and problems of conventional approaches in road pricing. He stated that since uniform pricing treats all travelers in the same way and ignores the variability in travelers' VTT, it overcharges many travelers while undercharging others. Therefore, he concluded that freeway users should be provided with several choices of price and level of service to be able to choose the option that charges them fairly. He used the term of "multi-pricing" for this pricing approach which can satisfy users and maximize the social welfare [4].

Shamanske is one of the first researchers who studied the benefit gained by toll discrimination. However, toll discrimination defined by Shmanske is different from the multi-lane pricing concept investigated here. Shmanske's toll discrimination approach allows those drivers with higher VTT to enjoy a shorter queue and thus shorter waiting time at toll plazas by paying a higher toll. He found that toll discrimination can reduce the total value of waiting time at toll plazas [5] [6]. However, electronic toll collection is used now and the concept of toll discrimination at a toll plaza is not applicable. But tolls that vary by lane may have a similar impact.

In this research, the benefits from saving travel time through the use of toll rates that vary by lane are investigated. Therefore, it is critical to use reasonable VTT. Most empirical studies of travel mode choices cannot separate many factors like comfort that affect the mode choice from the value of time [7]. As a result, it is more common to use stated preference data for determining VTT [8]. Since mixed logit model allows certain parameters in discrete choice models to vary within the population (according to a determined distribution), it is used to derive VTT from stated preference survey data [9].

Many studies conclude that VTT is dependent on income [7] [10]. In addition, Patil et al. found that travelers' value of travel time was much higher when they face urgent situations. They concluded that ignoring higher VTT for urgent trips and classifying them as ordinary trips could greatly underestimate the benefits from saved travel time [1]. In order to prevent underestimating VTT and benefits, mixed logit models of the VTT for three income groups and seven travel situations (including an ordinary situation and six urgent situations) developed by Patil et al. are used.

Clearly, having a roadway with different prices for travel on different lanes would have many logistical problems. Enforcement might be possible using closely spaced electronic toll collection readers. If the driver was observed in the higher priced lane by these readers then he/she would pay the higher toll—even if he/she had only switched lanes for a short time. However, in cases when there is a lane blockage there would need to be alternative policies in place to allow lane changing.

If the roadway was previously untolled then there would be public opposition to the idea and issues with equity. DeCorla-Souza has investigated potential methods to minimize the equity issue with ideas such as FAIR Lanes (Fast and Intertwined Regular lanes) [11]. However, ideas such as FAIR lanes and the one developed in our research come with many potential additional complications. This research is focused on the potential benefits of a "multi-pricing" policy. If the benefits are substantial the next step will be to investigate overcoming the practical hurdles to implementation.

\section{Methodology}

Patil et al. used SP data collected via an Internet survey of Katy Freeway travelers to develop mixed logit models in order to find VTT for an ordinary travel situation and six different urgent travel situations for three income groups [1]. Their estimated VTT distributions for an ordinary trip and five of urgent situations were used in this research (see Table 1). For example, VTT distributions for the high income group are shown in Figure 1. As 
Table 1. VTT used in this research.

\begin{tabular}{|c|c|c|c|c|}
\hline Situation & Description & $\begin{array}{l}\text { High Income Group } \\
\text { (greater than US } \$ 100,000 \text {, } \\
\text { annual household income) }\end{array}$ & $\begin{array}{l}\text { Medium Income Group } \\
\text { (US } \$ 50,000 \text { - 100,000, } \\
\text { annual household income) }\end{array}$ & $\begin{array}{l}\text { Low Income Group } \\
\text { (less than US } \$ 50,000 \text {, } \\
\text { annual household income) }\end{array}$ \\
\hline Ordinary & & $8.62-8.62 \times t_{\text {time }}$ & $7.38-7.38 \times t_{\text {time }}$ & $7.95-7.95 \times t_{\text {time }}$ \\
\hline $\begin{array}{l}\text { Important Appointment } \\
\text { (ImpAppt) }\end{array}$ & $\begin{array}{l}\text { Traveler needs to arrive on } \\
\text { time for an important } \\
\text { appointment/meeting/event }\end{array}$ & $23.23-23.23 \times t_{\text {time }}$ & $16-16 \times t_{\text {time }}$ & $18.95-18.95 \times t_{\text {time }}$ \\
\hline $\begin{array}{l}\text { Late Appointment } \\
\text { (LateAppt) }\end{array}$ & $\begin{array}{l}\text { Traveler is late and in need } \\
\text { of the fastest travel } \\
\text { alternative }\end{array}$ & $47.69-36.92 \times t_{\text {time }}$ & $27.76-21.5 \times t_{\text {time }}$ & $35.09-27.17 \times t_{\text {time }}$ \\
\hline Worry Time & $\begin{array}{l}\text { Traveler is worried about } \\
\text { arriving on time }\end{array}$ & $30.43-20.87 \times t_{\text {time }}$ & $21.65-14.85 \times t_{\text {time }}$ & $25.03-17.08 \times t_{\text {time }}$ \\
\hline $\begin{array}{l}\text { Late Managed } \\
\text { Lane (LateML) }\end{array}$ & $\begin{array}{l}\text { Traveler had left late since } \\
\text { he knows he can take } \\
\text { advantages of MLs } \\
\text { (or expensive lanes) }\end{array}$ & $20-16 \times t_{\text {time }}$ & $15.25-12.2 \times t_{\text {time }}$ & $17.3-13.84 \times t_{\text {time }}$ \\
\hline Extra Stops & $\begin{array}{l}\text { Traveler needs to make } \\
\text { extra stops on the trip but } \\
\text { still needs to arrive on time }\end{array}$ & $9.86-9.86 \times t_{\text {time }}$ & $8.27-8.27 \times t_{\text {time }}$ & $9-9 \times t_{\text {time }}$ \\
\hline
\end{tabular}

$t_{\text {time }}$ is randomly drawn from a triangular distribution $(-1,1)$ with a mean of 0 .

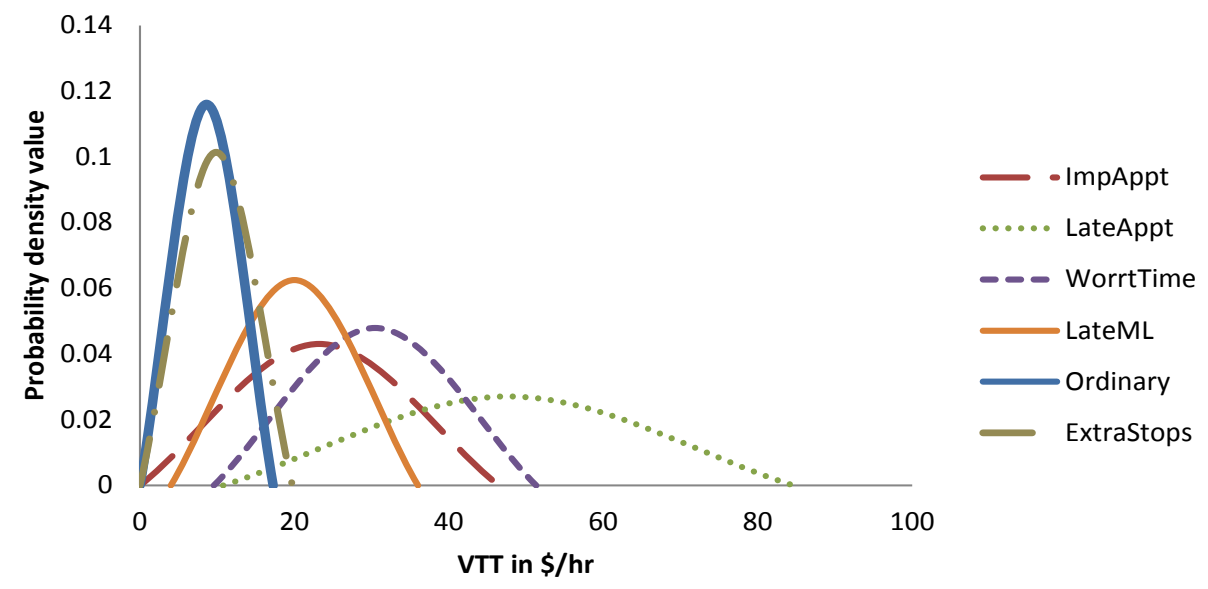

Figure 1. VTT distributions for the high income group.

expected, high income travelers also had the highest VTT. It is interesting to note that low income travelers had higher VTT than medium income travelers. This may be due to time constraints that are placed on the low income travelers, particularly inflexible work starting times.

\subsection{Traveler Characteristics}

To be able to use the VTT distributions shown in Table 1, reasonable assumptions about the percent of drivers in each group of travelers was necessary. In this research, assumptions regarding these percentages were based on a mix of traveler survey data in Houston and census data from Houston. They were as follows:

1) Percent of travelers with low income $=25 \%$,

2) Percent of travelers with medium income $=37 \%$,

3) Percent of travelers with high income $=38 \%$,

4) The percentage of travelers who are facing an urgent trip will vary from 0 percent to 30 percent. For those travelers who are facing an urgent situation, the distribution of urgent situations was arbitrarily set as follows:

- $20 \%$ face urgent situation-Important Appointment,

- $20 \%$ face urgent situation-Late Appointment, 
- $20 \%$ face urgent situation-Worry Time,

- $20 \%$ face urgent situation-Late Managed Lane,

- 20\% face urgent situation-Extra Stops.

These assumptions can be changed to see how travel times are impacted by the number of travelers in each urgent trip situation. However, in this research, these percentages will remain constant as other variables (the percent of total urgent trips and volume of traffic) are varied.

\subsection{Road Characteristics}

In this study a roadway segment with following characteristics was assumed:

1) Length of segment $=10$ miles

2) Free flow speed $=75 \mathrm{mph}$

3) Total number of lanes $=4$ lanes in each direction

- One expensive lane;

- Two moderate lanes;

- One cheap lane.

Again, all these characteristics can be changed to examine their impact on travel time from this differential tolling idea.

\subsection{Travel Time Calculation}

In this research, Equation (1) is used to calculate travel delay and travel time.

$$
T=T_{f}\left[1+a \times\left(\frac{V}{V_{k}}\right)^{b}\right],
$$

where:

$T$ = Travel time;

$T_{f}=$ Travel time with free flow speed;

$V=$ Total volume on the lane(s);

$V_{k}=$ Capacity of the lane(s).

This function with parameter values $a=0.15$ and $b=4$ is known as the Bureau of Public Roads (BPR) function, and with $a=0.2$ (for freeways) and $b=10$ is known as the "updated BPR function" [12]. The updated BPR function is used to calculate travel time in this research.

\subsection{Travel Time Savings Calculation}

There are 18 groups of travelers (6 different situations for each of 3 income groups), and the objective is to minimize the total value of travel time of travelers (TVTT) on this section of road. If $i$ (1 to18) represents a group of travelers and $j$ ( 1 to 3 ) represents a lane category (expensive, moderate and free):

$$
\begin{aligned}
& \text { TVTT }=\sum_{i=1}^{i=18} \mathrm{VTT}_{i}, \\
& \operatorname{VTT}_{i}=\sum_{j=1}^{j=3} \mathrm{NT}_{i j} \times \mathrm{TT}_{j} \times \mathrm{AVTT}_{i j},
\end{aligned}
$$

where:

TVTT = Total value of travel time (\$);

$\mathrm{VTT}_{i}=$ Value of travel time for group $i$ of travelers (\$);

$\mathrm{NT}_{i j}=$ Number of travelers from group $i$ in lane category $j$;

$\mathrm{TT}_{j}=$ Travel time in lane category $j$ (min);

$\operatorname{AVTT}_{i j}=$ Average value of travel time for travelers from group $i$ in lane category $j(\$ / \mathrm{min})$.

$\mathrm{AVTT}_{i j}$ and $\mathrm{NT}_{i j}$ are dependent on the toll rates; and $\mathrm{TT}_{j}$ is dependent on volume in each lane. Equation (4) is used to calculate $\mathrm{TT}_{j}$ :

$$
\mathrm{TT}_{j}=T_{f}\left(1+0.2\left(\frac{\sum_{i=1}^{18} \mathrm{NT}_{i j}}{N_{j} \times 1800}\right)^{10}\right),
$$


where:

$N_{j}$ : Number of lanes for lane category $j$.

This research compares a uniform toll rate strategy with a differential (or multi-pricing) toll rate strategy; it should be noted that the potential impacts of differential toll rates on demand would not be more than the impacts of uniform pricing. This is because there is a lane that is cheaper than the uniform toll rate when differential toll rates are used. Therefore, some travelers who might have been priced off a toll road would shift to the cheap lane under a differential toll rate strategy. In this paper, uniform pricing does not mean that prices do not vary by time; it means that prices are the same for all lanes. Therefore, if the differential toll rates are found to be more beneficial than uniform toll rates, it can be combined with other types of pricing including variable or dynamic pricing. Excel solver is used to find the toll rates which minimize the total value of travel time.

Next is a simplified example of how optimum toll rates are found. In this example, the only travelers on the roadway are high income travelers who face the urgent situation: they are running late but know a managed lane option is available (Late Managed Lane), instead of having all 18 traveler categories. The pdf of VTT for these travelers can be seen in Figure 1 which is used in Equations (5), (6), (7), (11), (12) and (13). Also assume there are 8000 of these travelers in the peak hour and their VTT is distributed as shown in Figure 2.

Figure 2 is derived from the Equation for VTT for high income drivers who face LateML situation (see Table 1) which is:

$$
\mathrm{VTT}_{\text {(high incomel LateML) }}=20-16 \times t_{\text {time }} \text {. }
$$

$t_{\text {time }}$ is randomly drawn from a triangular distribution $(-1,1)$ with a mean of 0 . Therefore, the $\mathrm{VTT}_{\text {(high in- }}$ comelLateML) distribution is a triangular distribution $(4,36)$ with a mean of 20 . Thus, the Equations for left side and right side of the triangle are:

$$
\begin{aligned}
& \text { Left side }:(x-4) \times 0.0039, \\
& \text { Right side }:(20-x) \times 0.0039+0.0625 \text {. }
\end{aligned}
$$

The number of travelers in each lane category can be obtained using Equations (5), (6) and (7). It is assumed that travelers with a VTT lower than moderate toll rate (MTR) will use the cheap lane; travelers with a VTT between moderate and expensive toll rates (ETR) will use moderate lanes, and those with a VTT higher than expensive toll rate will use the expensive lane (EL). The ratio of travelers in the cheap, moderate and expensive lanes are determined by the area under the pdf curve for VTT smaller than MTR (Equation (5)), the area under the pdf curve for VTT between MTR and ETR (Equation (6)) and the area under the pdf curve for VTT larger than ETR (Equation (7)).

Lane 1: Cheap lane;

Lane 2: Two moderate lanes;

Lane 3: Expensive lane.

MINIMIZE: $\mathrm{TVTT}=\sum_{j=1}^{j=3} \mathrm{NT}_{j} \times \mathrm{TT}_{j} \times \mathrm{AVTT}_{j}$,

Subject to:

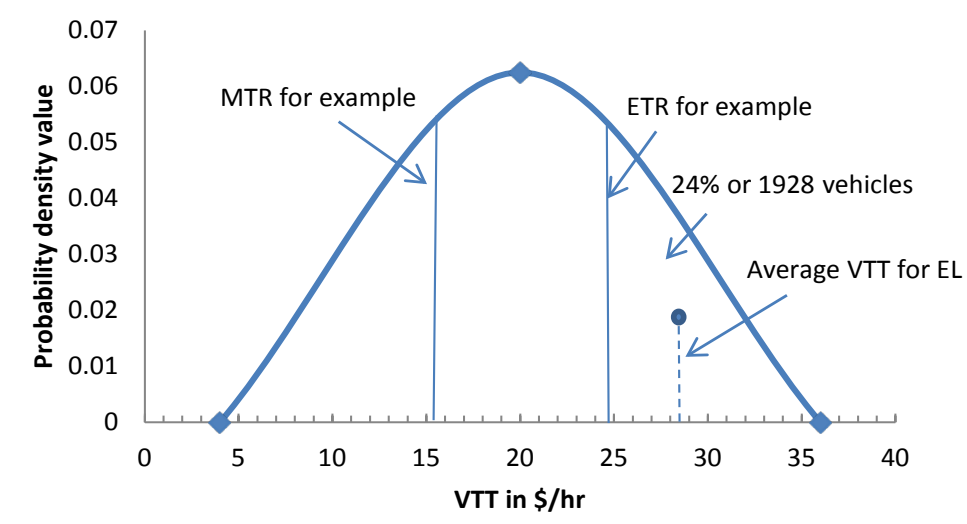

Figure 2. VTT distributions for the high income travelers who face LateML situation. 


$$
\begin{aligned}
& \frac{\mathrm{NT}_{1}}{8000}= \begin{cases}\int_{x=4}^{x=\mathrm{MTR}}[(X-4) \times 0.0039] \mathrm{d} x & \text { if } \mathrm{MTR}<\frac{\$ 20}{\mathrm{hr}}, \\
0.5+\int_{x=20}^{x=\mathrm{MTR}}[(20-X) \times 0.0039+0.0625] \mathrm{d} x & \text { if } \mathrm{MTR}>\frac{\$ 20}{\mathrm{hr}},\end{cases} \\
& \frac{\mathrm{NT}_{2}}{8000}= \begin{cases}\int_{x=\mathrm{MTR}}^{x=\mathrm{ETR}}[(X-4) \times 0.0039] \mathrm{d} x & \text { if } \mathrm{ETR}<\frac{\$ 20}{\mathrm{hr}}, \\
\int_{x=\mathrm{MTR}}^{x=20}[(X-4) \times 0.0039] \mathrm{d} x+\int_{x=20}^{x=\mathrm{ETR}}[(20-X) \times 0.0039+0.0625] \mathrm{d} x & \text { if } \mathrm{MTR}<\frac{\$ 20}{\mathrm{hr}}, \mathrm{ETR}>\frac{\$ 20}{\mathrm{hr}},(6) \\
\int_{x=\mathrm{MTR}}^{x=\mathrm{ETR}}[(20-X) \times 0.0039+0.0625] \mathrm{d} x & \text { if MTR }>\frac{\$ 20}{\mathrm{hr}},\end{cases} \\
& \frac{\mathrm{NT}_{3}}{8000}= \begin{cases}\int_{x=\mathrm{ETR}}^{x=36}[(20-X) \times 0.0039+0.0625] \mathrm{d} x & \text { if ETR }>\frac{\$ 20}{\mathrm{hr}}, \\
0.5+\int_{x=\mathrm{MTR}}^{x=20}[(X-4) \times 0.0039] \mathrm{d} x & \text { if ETR }<\frac{\$ 20}{\mathrm{hr}},\end{cases}
\end{aligned}
$$

Using the number of travelers in each lane category and travel time function (Equation (4)) travel time in each lane category is calculated (Equations (8), (9) and (10)). The average value of travel time for travelers in each lane category can be obtained using Equations (11), (12) and (13).

$$
\begin{aligned}
& \mathrm{TT}_{1}=\frac{10}{75} \times 60 \times\left(1+0.2\left(\frac{\mathrm{NT}_{1}}{1 \times 1800}\right)^{10}\right), \\
& \mathrm{TT}_{2}=\frac{10}{75} \times 60 \times\left(1+0.2\left(\frac{\mathrm{NT}_{2}}{2 \times 1800}\right)^{10}\right), \\
& \mathrm{TT}_{3}=\frac{10}{75} \times 60 \times\left(1+0.2\left(\frac{\mathrm{NT}_{3}}{1 \times 1800}\right)^{10}\right),
\end{aligned}
$$

The average value of travel time for travelers in the cheap, moderate and expensive lanes are the centroid of the area under the pdf curve for VTT smaller than MTR (Equation (11)), the centroid of the area under the pdf curve for VTT between MTR and ETR (Equation (12)) and the centroid of the area under the pdf curve for VTT larger than ETR (Equation (13)).

$$
\mathrm{AVTT}_{1} \times 60= \begin{cases}\frac{\int_{x=4}^{x=\mathrm{MTR}} X[(X-4) \times 0.0039] \mathrm{d} x}{\mathrm{NT}_{1} / 8000} & \text { if } \mathrm{MTR}<\frac{\$ 20}{\mathrm{hr}}, \\ \frac{0.5 \times 14.7+\int_{x=20}^{x=\mathrm{MTR}} X[(20-X) \times 0.0039+0.0625] \mathrm{d} x}{\mathrm{NT}_{1} / 8000} & \text { if } \mathrm{MTR}>\frac{\$ 20}{\mathrm{hr}},\end{cases}
$$

$\mathrm{AVTT}_{2} \times 60$

$$
= \begin{cases}\frac{\int_{x=\mathrm{MTR}}^{x=\mathrm{ETR}} X[(X-4) \times 0.0039] \mathrm{d} x}{\mathrm{NT}_{2} / 8000} & \text { if } \mathrm{ETR}<\frac{\$ 20}{\mathrm{hr}}, \\ \frac{\int_{x=\mathrm{MTR}}^{x=20} X[(X-4) \times 0.0039] \mathrm{d} x+\int_{x=20}^{x=\mathrm{ETR}} X[(20-X) \times 0.0039+0.0625] \mathrm{d} x}{\mathrm{NT}_{2} / 8000} & \text { if } \mathrm{MTR}<\frac{\$ 20}{\mathrm{hr}}, \mathrm{ETR}>\frac{\$ 20}{\mathrm{hr}}, \\ \frac{\int_{x=\mathrm{MTR}}^{x=\mathrm{ETR}} X[(20-X) \times 0.0039+0.0625] \mathrm{d} x}{\mathrm{NT}_{2} / 8000} & \text { if MTR }>\frac{\$ 20}{\mathrm{hr}},\end{cases}
$$




$$
\mathrm{AVTT}_{3} \times 60= \begin{cases}\frac{\int_{x=\mathrm{ETR}}^{x=36} X[(20-X) \times 0.0039+0.0625] \mathrm{d} x}{\mathrm{NT}_{3} / 8000} & \text { if ETR }>\frac{\$ 20}{\mathrm{hr}}, \\ \frac{\int_{x=\mathrm{MTR}}^{x=20} X[(X-4) \times 0.0039] \mathrm{d} x+0.5 \times 25.3}{\mathrm{NT}_{3} / 8000} & \text { if ETR }<\frac{\$ 20}{\mathrm{hr}},\end{cases}
$$

The minimum TVTT will be obtained by setting the ETR at $\$ 24.9 / \mathrm{hr}$ and the MTR at $\$ 15.6 / \mathrm{hr}$. The benefit is the value of travel time saved using these toll rates versus a scenario where all vehicles pay the same or no toll (Equation (14)). Table 2 shows the travel time and toll for each lane category in this example.

$$
\begin{aligned}
& \text { Benefit }=\mathrm{TVTT}_{\text {uniform toll }}-\mathrm{TVTT}_{\text {differential tolls }} \cdot \\
& \mathrm{TVTT}_{\text {uniform toll }}=8000 \times\left[\frac{10 \mathrm{mile}}{75 \mathrm{mph}} \times 60 \mathrm{~min} \times\left(1+0.2 \times\left(\frac{8000}{4 \times 1800}\right)^{10}\right)\right] \times \frac{\$ 20}{\mathrm{hr}} \times \frac{1 \mathrm{hr}}{60 \mathrm{~min}}, \\
& \rightarrow \mathrm{TVTT}_{\text {uniform toll }}=8000 \times 12.59 \times \frac{20}{60}=33570, \\
& \mathrm{TVTT}_{\text {differential tolls }}=1928 \times 11.19 \times \frac{28.59}{60}+3981 \times 12.37 \times \frac{20.19}{60}+2091 \times 15.16 \times \frac{11.71}{60}=33038 .
\end{aligned}
$$

The tolls found here are the relative toll rates which mean that the moderate toll and expensive toll should be \$0.72 and \$1.65 more than the cheap toll, respectively. The actual toll rates are dependent on the uniform toll rate that was charged previously. The moderate toll rate could be set as the same price as previous uniform toll

\begin{tabular}{|c|c|c|c|c|c|c|c|c|}
\hline \multicolumn{6}{|c|}{ Differential Toll Rates Strategy } & \multicolumn{3}{|c|}{ Uniform Toll Rate Strategy } \\
\hline Benefit (\$/h) & Lane Category & Volume & $\begin{array}{c}\text { Average } \\
\text { value of travel } \\
\text { time }(\$ / \mathrm{h})\end{array}$ & $\begin{array}{l}\text { Travel } \\
\text { Time } \\
\text { (min) }\end{array}$ & $\begin{array}{l}\text { Relative } \\
\text { Toll (\$) }\end{array}$ & $\begin{array}{c}\text { Volume } \\
\text { on each } \\
\text { lane }\end{array}$ & $\begin{array}{l}\text { Travel time } \\
\text { (min) }\end{array}$ & $\begin{array}{c}\text { Average } \\
\text { value of travel } \\
\text { time }(\$ / h)\end{array}$ \\
\hline \multirow{3}{*}{532} & Expensive Lane & 1928 & 28.59 & 11.19 & 1.65 & & & \\
\hline & Moderate Lanes & 3981 & 20.19 & 12.37 & 0.72 & 2000 & 12.59 & 20.00 \\
\hline & Cheap Lane & 2091 & 11.71 & 15.16 & - & & & \\
\hline
\end{tabular}
rate. Then, the expensive toll rate and cheap toll rate can be found using the relative toll rates shown in the Table 2. For example, if the uniform toll rate was $\$ 2$ previously, the cheap, moderate and expensive toll rate would be \$1.28, \$2 and \$2.93, respectively.

Table 2. Optimum tolls and travel time for the example.

This example only reduced the value of time spent traveling by $1.6 \%$ (\$532/\$33570). These benefits will increase when including more variety in VTT and groups of travelers as outlined in the results section.

\section{Results}

The above approach was then expanded for all 18 groups of travelers. The total benefit for different traffic volumes and different percentages of urgent trips was calculated. Figure 3 and Table 3 show how total benefits change with respect to the change in total vehicle volumes and the percentage of urgent trips.

As expected, the benefit increases as congestion increases and as more travelers face urgent trips (since their VTT increases). The travel time on the moderate lanes is similar to the travel time with a uniform toll rate. Therefore, the change is primarily between travelers moving to the expensive and free lanes. Travelers in expensive lanes benefit most from the different toll rate strategy, while travelers in free lanes lose some travel time by moving to this strategy. Overall, because of the high VTT for travelers in expensive lanes and low VTT for travelers in free lanes, there is a net benefit in using the differential toll rates strategy. 
Table 3. Differential rates strategy results.

\begin{tabular}{|c|c|c|c|c|c|c|c|c|c|}
\hline & $\begin{array}{l}\text { Volume } \\
\text { (vph) }\end{array}$ & $\begin{array}{l}\text { Total } \\
\text { Benefit } \\
(\$ / h)\end{array}$ & $\begin{array}{l}\text { VTT } \\
\text { Saving } \\
\text { (\%) }\end{array}$ & $\begin{array}{c}\text { Travel Time } \\
\text { with Same Toll } \\
\text { Rates (min) }\end{array}$ & $\begin{array}{l}\text { Relative Toll } \\
\text { for Moderate } \\
\text { Lane (\$) }\end{array}$ & $\begin{array}{c}\text { Relative Toll } \\
\text { for Expensive } \\
\text { Lane (\$) }\end{array}$ & $\begin{array}{c}\text { Cheap Lane } \\
\text { Travel Time } \\
\text { (min) }\end{array}$ & $\begin{array}{c}\text { Moderate } \\
\text { Lane Travel } \\
\text { Time (min) }\end{array}$ & $\begin{array}{c}\text { Expensive } \\
\text { Lane Travel } \\
\text { Time (min) }\end{array}$ \\
\hline \multirow{5}{*}{$\begin{array}{l}30 \% \\
\text { urgent } \\
\text { trip }\end{array}$} & 7000 & 286 & 2.19 & 9.21 & 0.16 & 0.49 & 10.63 & 9.21 & 8.52 \\
\hline & 8000 & 1241 & 6.09 & 12.59 & 0.60 & 1.88 & 18.00 & 12.59 & 9.97 \\
\hline & 8500 & 2418 & 8.56 & 16.41 & 1.11 & 3.45 & 26.33 & 16.41 & 11.62 \\
\hline & 9000 & 4535 & 10.86 & 22.90 & 1.96 & 6.10 & 40.47 & 22.90 & 14.40 \\
\hline & 9500 & 8219 & 12.72 & 33.59 & 3.36 & 10.48 & 63.75 & 33.59 & 19.00 \\
\hline \multirow{5}{*}{$\begin{array}{l}20 \% \\
\text { urgent } \\
\text { trip }\end{array}$} & 7000 & 217 & 1.88 & 9.21 & 0.14 & 0.40 & 10.49 & 9.21 & 8.55 \\
\hline & 8000 & 945 & 5.23 & 12.59 & 0.52 & 1.52 & 17.46 & 12.59 & 10.10 \\
\hline & 8500 & 1840 & 7.35 & 16.41 & 0.94 & 2.79 & 25.34 & 16.41 & 11.86 \\
\hline & 9000 & 3451 & 9.33 & 22.90 & 1.67 & 4.94 & 38.72 & 22.90 & 14.83 \\
\hline & 9500 & 6255 & 10.93 & 33.59 & 2.87 & 8.47 & 60.74 & 33.59 & 19.73 \\
\hline \multirow{5}{*}{$\begin{array}{l}10 \% \\
\text { urgent } \\
\text { trip }\end{array}$} & 7000 & 146 & 1.45 & 9.21 & 0.12 & 0.32 & 10.33 & 9.18 & 8.62 \\
\hline & 8000 & 635 & 4.03 & 12.59 & 0.44 & 1.22 & 16.87 & 12.50 & 10.36 \\
\hline & 8500 & 1236 & 5.67 & 16.41 & 0.81 & 2.25 & 24.26 & 16.25 & 12.34 \\
\hline & 9000 & 2318 & 7.19 & 22.90 & 1.43 & 3.98 & 36.80 & 22.61 & 15.68 \\
\hline & 9500 & 4202 & 8.42 & 33.59 & 2.46 & 6.83 & 57.45 & 33.08 & 21.19 \\
\hline
\end{tabular}

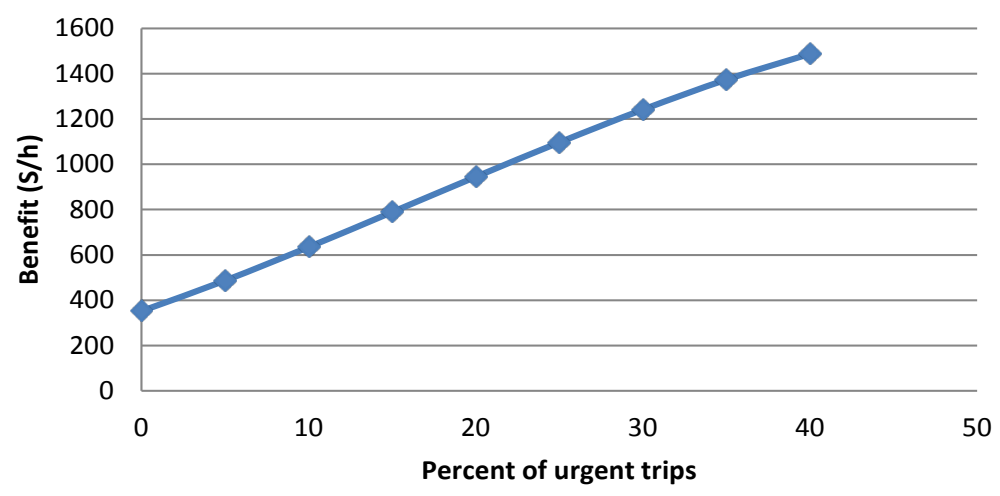

Figure 3. VTT distributions for the high income travelers who face LateML Situation

The benefits range a great deal depending on the variety of VTT in traffic. In the example, there was only a $\$ 530$ net benefit. Using the same traffic condition (8000 vph) but all 18 groups of travelers with 20 percent facing urgent trips, this benefit increases to $\$ 945$, or 5.2 percent of the value of travel time. It is not until the facility becomes congested do benefits become substantial. For example, at $9000 \mathrm{vph}$ with 20 percent urgent trips the total value of time spent traveling in the uniform tolling scenario is \$36982 and in deferential tolling strategy is \$33531, a saving of $9.3 \%$. The savings increase to $10.9 \%$ as the percent of urgent trips increases to 30 percent.

As with Table 2, the toll rates provided in Table 3 are set relative to the toll in the cheap lanes. The table shows rates with respect to a free cheap lane, but the results would be the same if all three lane categories charged another dollar. This is because of the simplifying assumption that demand is fixed for each scenario and does not depend on the toll. Clearly demand would change based on the toll rate. However, if the median lane toll price were set at the same rate as a toll road that previous operated with uniform rates, the impact on demand would be minimal. 


\section{Toll Road Express Lanes Example}

In this second example, a conventional 5 lane (per direction) toll facility is converted into a toll facility with 2 express lanes (more expensive lanes) and 3 cheap toll lanes. All other assumptions (10 mile length, updated BPR relationship between speed and flow, 18 groups of travelers, etc.) remain the same. It is assumed that 20 percent of travelers are facing urgent travel situations. The analysis indicates that there are VTT benefits from this strategy versus a toll facility with a uniform toll rate on all lanes (see Table 4).

Table 4. VTT savings for express lanes on a toll road.

\begin{tabular}{cccccccc}
\hline $\begin{array}{c}\text { Volume } \\
\text { (vph) }\end{array}$ & $\begin{array}{c}\text { TVTT with } \\
\text { Uniform } \\
\text { Toll }(\$)\end{array}$ & $\begin{array}{c}\text { TVTT with } \\
\text { Differential } \\
\text { Toll Rates }(\$)\end{array}$ & $\begin{array}{c}\text { VTT } \\
\text { Saving } \\
(\%)\end{array}$ & $\begin{array}{c}\text { Relative Toll } \\
\text { for Expensive } \\
\text { Lanes }(\$)\end{array}$ & $\begin{array}{c}\text { Travel Time } \\
\text { with Uniform } \\
\text { Toll (min) }\end{array}$ & $\begin{array}{c}\text { Travel Time } \\
\text { for Cheap } \\
\text { Lanes (min) }\end{array}$ & $\begin{array}{c}\text { Travel Time } \\
\text { for Expensive } \\
\text { Lanes (min) }\end{array}$ \\
\hline 10000 & 21199 & 20480 & 3.39 & 0.54 & 11.81 & 13.40 & 10.20 \\
11000 & 31929 & 30233 & 5.31 & 1.17 & 16.18 & 19.58 & 12.71 \\
11500 & 40586 & 38056 & 6.23 & 1.67 & 19.67 & 24.52 & 14.72 \\
12000 & 52542 & 48831 & 7.06 & 2.34 & 24.40 & 31.22 & 17.45 \\
12500 & 68939 & 63581 & 7.77 & 3.24 & 30.74 & 40.19 & 21.10 \\
\hline
\end{tabular}

\section{Conclusion}

In this research, VTT distributions developed by Patil et al. (1) were used to investigate the possible benefits of different toll rates versus a uniform toll rate for a roadway. In the differential toll rates strategy, the roadway was divided into cheap, moderate and expensive lanes. In the uniform toll rates strategy, all lanes had the same toll rates (which could also be free). It was found that significant benefits could be gained from the differential toll rates strategy for a congested roadway. The benefit increased as the volume and numbers of travelers facing urgent trips increased. For example, when the volume was $9000 \mathrm{vph}$ in four lanes and 20 percent of travelers were facing an unusual/urgent trip, the total value of travel times could be reduced by $9.3 \%$ using differential toll rate strategy.

\section{Future Studies}

The estimated benefits have a direct relationship with the travel time function. Therefore, a sensitivity analysis on the influence of the parameters of this function can be undertaken. Also, real travel time data for a similar roadway can be used to calibrate these parameters. Moreover, the assumption that travelers with different VTT use the designated lane may be unrealistic; this assumption would be more close to reality if travelers know the travel time of each lane in advance. Studies are needed to find how actual travel time saved is valued differently from what travelers believe they will save by choosing each lane.

\section{References}

[1] Patil, S., Burris, M., Shaw, D. and Concas, S. (2011) Variation in the Value of Travel Time Savings and Its Impact on the Benefits of Managed Lanes. Transportation Planning and Technology, 34, 547-567. http://dx.doi.org/10.1080/03081060.2011.600068

[2] Sullivan, E.C. and Burris, M. W. (2006) Benefit-Cost Analysis of Variable Pricing Projects: SR-91 Express Lanes. Journal of Transportation Engineering, 132, 191-198. http://dx.doi.org/10.1061/(ASCE)0733-947X(2006)132:3(191)

[3] Burris, M.W. and Sullivan, E.C. (2006) Benefit-Cost Analysis of Variable Pricing Projects: QuickRide HOT Lanes. Journal of Transportation Engineering, 132, 183-190. http://dx.doi.org/10.1061/(ASCE)0733-947X(2006)132:3(183)

[4] Poole, R.W. (2012) Gaining Public Support for Freeway Congestion Pricing. No. Public Study 401, Reason Foundation.

[5] Shmanske, S. (1991) Price Discrimination and Congestion. National Tax Journal, 44, 529-532.

[6] Shmanske, S. (1993) A Simulation of Price-Discriminating Tolls. Journal of Transport Economics and Policy, 27, 225-235. 
[7] Concas, S. and Kolpakov, A. (2009) Synthesis of Research on Value of Time and Value of Reliability. No. BD54946.

[8] Maricopa Association of Governments (2012) Toll Roads Modeling Support. Final Report No. 164860.

[9] Fodgerau, M. (2006) Investigating the Distribution of the Value of Travel Time Savings. Journal of Transportation Research Part B, 40, 688-707. http://dx.doi.org/10.1016/j.trb.2005.09.007

[10] Mackie, P.J., Wardman, M., Fowkes, A.S., Whelan, G., NEllthorp, J. and Bates, J. (2003) Values of Travel Time Savings in UK. Report to Department of Transport.

[11] DeCorla-Souza, P. (2003) Evaluation of Toll Options Using Quick-Response Analysis Tools Case Study of the Capital Beltway. Transportation Research Record: Journal of the Transportation Research Board, 1839, 65-73. http://dx.doi.org/10.3141/1839-06

[12] Small, K.A. and Verhoef, T. E. (2007) The Economics of Urban Transportation. Routledge, London. 
Scientific Research Publishing (SCIRP) is one of the largest Open Access journal publishers. It is currently publishing more than 200 open access, online, peer-reviewed journals covering a wide range of academic disciplines. SCIRP serves the worldwide academic communities and contributes to the progress and application of science with its publication.

Other selected journals from SCIRP are listed as below. Submit your manuscript to us via either submit@scirp.org or Online Submission Portal.
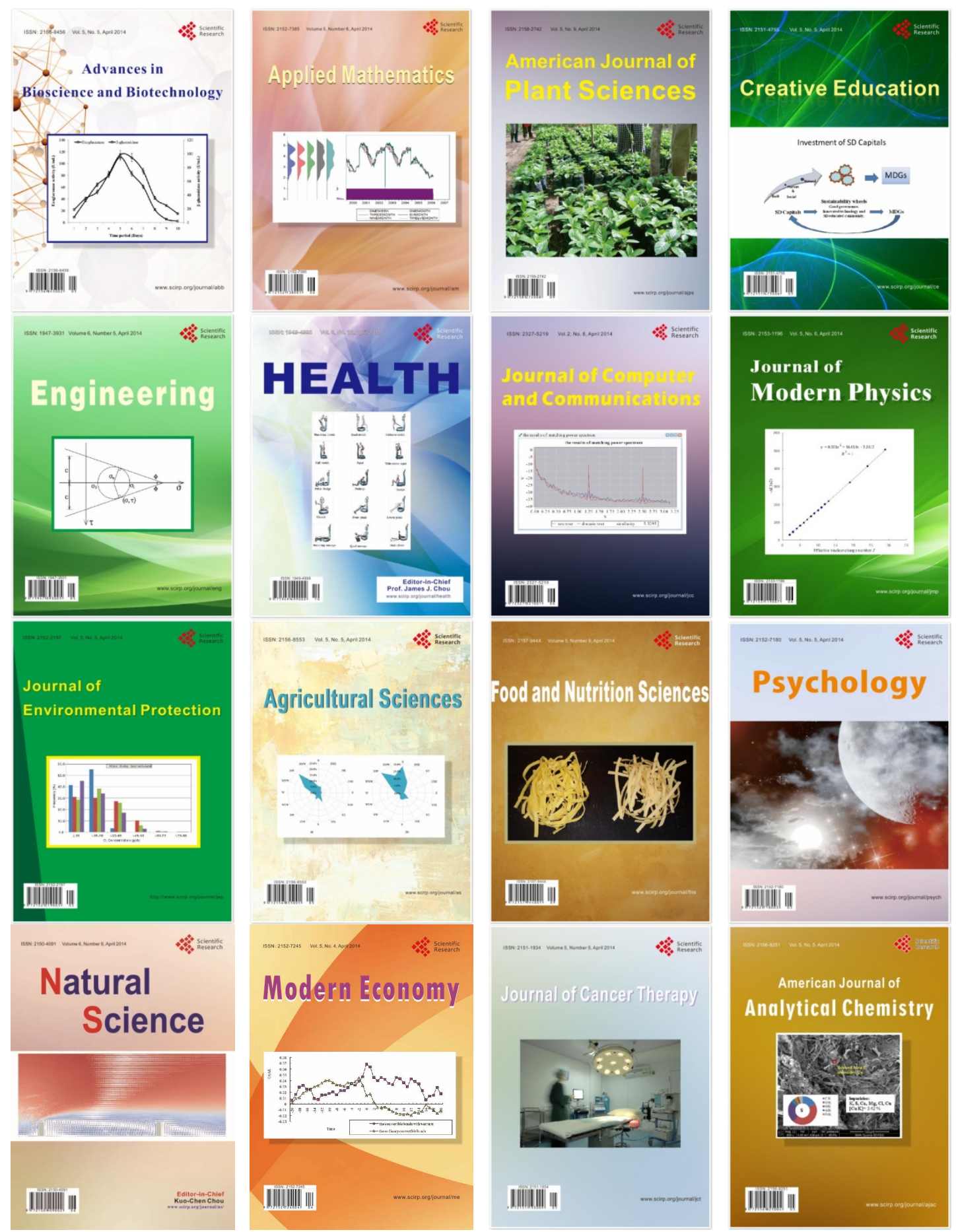